Review Article

\title{
Cross-Talk between Gut Microbiota and Heart via the Routes of Metabolite and Immunity
}

\author{
Jin Bu and Zhaohui Wang (D) \\ Department of Geriatrics, Union Hospital, Tongji Medical College, Huazhong University of Science and Technology, \\ Wuhan 430022, China \\ Correspondence should be addressed to Zhaohui Wang; wwwzh129@163.com
}

Received 25 March 2018; Accepted 16 May 2018; Published 3 June 2018

Academic Editor: Joanne Bowen

Copyright (c) 2018 Jin Bu and Zhaohui Wang. This is an open access article distributed under the Creative Commons Attribution License, which permits unrestricted use, distribution, and reproduction in any medium, provided the original work is properly cited.

\begin{abstract}
Considering the prevalence of cardiovascular disease (CVD), significant interest has been focused on the gut microbiota-heart interaction because the gut microbiota has been recognized as a barometer of human health. Dysbiosis, characterized by changes in the gut microbiota in CVD, has been reported in cardiovascular pathologies, such as atherosclerosis, hypertension, and heart failure. Conversely, gut microbiota-derived metabolites, such as trimethylamine/trimethylamine $N$-oxide (TMA/TMAO), can impact host physiology. Further, bacterial dysbiosis can disturb gut immunity, which increases the risk of acute arterial events. Moreover, studies of germ-free mice have provided evidence that microbiota diversity and the presence of a specific microbe in the gut can affect immune cells in hosts. Therefore, the changes in the composition of the gut microbiota can affect host metabolism and immunity. Importantly, these effects are not only confined to the gut but also spreaded to distal organs. The purpose of the current review is to highlight the complex interplay between the microbiota and CVD via TMAO and different immune cells and discuss the roles of probiotics and nutrition interventions in modulating the intestinal microbiota as novel therapeutic targets of CVD.
\end{abstract}

\section{Introduction}

Paralleling the improvement of the social economy and aging population, cardiovascular disease (CVD) becomes the leading cause of death and disability worldwide. According to the American Heart Association, the overall rate of death attributable to CVD in 2013 was 222.9 per 100,000 Americans, accounting for $35 \%$ of deaths before the age of 75 years [1]. Cardiovascular health including health behaviors (e.g., healthy dietary pattern, appropriate energy balance, and nonsmoking) and health factors (e.g., optimal blood lipid level and blood pressure (BP)) has been recently defined as the primary goals. The role of the ecological system consisting of gut commensal bacteria in cardiovascular health becomes the focus of the current research.

In CVD, the ratio and abundance of the gut microbiota change and interventions using prebiotics, probiotics, and synbiotics share similar therapeutic efficacies in attenuating cardiac dysfunctions. Moreover, accumulating evidence indicates that bacterial dysbiosis increases cardiometabolic risks. It is likely that the gut microbiota substantially contributes to the global epidemic of CVD.

The microbiota in the gut, coevolving with the host, mainly colonizes in the colon. It can perform multiple functions, such as fermentation of nondigestible dietary substances, control of intestinal epithelial cell proliferation, and prevention from propagation of pathogenic microorganisms $[2,3]$. Accumulating evidence also shows that manipulation of the composition of the gut microbiota affects host metabolism and immunity [4], whereas the effect is not only confined to the intestine but also spreaded to distal organs through different pathways $[5,6]$. In this review, we aimed to discuss the compositional and functional changes in the gut microbiota in relation to CVD, determine the effects of 
the gut microbiota on CVD from the view of trimethylamine $\mathrm{N}$-oxide (TMAO) and immune cells, and evaluate how gut interventions can lead to novel therapeutic targets for CVD.

\section{Changes in the Composition of the Gut Microbiota in CVD}

The development of high-throughput sequencing of nucleic acids (i.e., DNA and RNA) for taxonomic mapping allows the identification of the origins and composition of the microbiota [7]. After birth, the intestinal tract is colonized by nonpathogenic microorganisms and maintains a coexisting and symbiotic relationship with microbial ecology, which evolves over time and is susceptible to both exogenous and endogenous modifications. Generally, 35,000 species of the gut microbiota have been classified into five phyla (i.e., Bacteroidetes, Firmicutes, Actinobacteria, Proteobacteria, and Verrucomicrobia). The composition and ratio of the intestinal flora seem to change during the pathogenesis of CVD (Table 1).

The previous observation in patients of atherosclerosis (AS) that the abundances of Veillonella and Streptococcus in atherosclerotic plaques were correlated with their abundance in the oral cavity first suggested that the plaque microbiota may be partly derived from the oral cavity and/or the gut [8]. Furthermore, periodontal pathogens may in turn influence plaque composition and rupture, accompanying with increasing risks for coronary artery disease [9]. Interestingly, patients with symptomatic AS had a higher relative abundance of Anaeroglobus in the oral cavity than asymptomatic AS control [10]. Patients with symptomatic AS demonstrated enriched genus Collinsella in the gut compared to healthy controls; gut metagenome may be associated with the inflammatory status of the host [11]. Taken together, these data seem to suggest that the gut microbiome is more proinflammatory in patients with CVD [12]. Specially, large-scale clinical research on patients with coronary AS demonstrated that the abundances of Enterobacteriaceae and Streptococcus increased, while those of probiotics (Clostridium) decreased [13]. Patients with heart failure (HF) showed significantly decreased diversity of the intestinal microbiome and downregulated key intestinal bacterial groups [14]. Older patients had diminished proportions of Bacteroidetes and larger quantities of Proteobacteria and enriched Lactobacillus [15] compared to younger patients with HF.

Studies on $\mathrm{APOE}^{-I-}$ rats provided direct evidence that AS susceptibility within a host may be influenced by gut (cecal) microbial transplantation. Cecal microbial transplantation from AS-prone versus AS-resistant inbred strains of mice enhanced choline diet-dependent AS. The study also revealed that Prevotella was positively correlated with atherosclerotic plaque lesions [16]. On the 7th day after surgery for acute myocardial infarction (AMI) in a previous study, the abundance of the gut microbiota, such as the Synergistetes phylum and Lachnospiraceae family, significantly increased, paralleling gut barrier impairment [17]. Bacteria from the phyla Bacteroidetes and Firmicutes were prevalent in spontaneous hypertensive rats. These findings suggest that bacteria from the oral cavity and perhaps even the gut may correlate with disease progression of CVD.

\section{Gut Microbiota-Derived Metabolite: TMAO and CVD}

The gut microbiota can elicit effects on the host through bioactive metabolisms. Recent research studies have established that TMAO, an intestinal microbiota metabolite of choline and phosphatidylcholine, can increase the risk of incident major adverse cardiovascular events $[18,19]$. Initially, Wang et al. found that the three metabolites of the dietary lipid phosphatidylcholine, namely, choline, TMAO, and betaine, predicted the risk for CVD in an independent large clinical cohort [5]. Then, they found that omnivorous human subjects produced more TMAO than vegans or vegetarians following the same ingestion. Furthermore, oral broadspectrum antibiotics to suppress the intestinal microbiota can suppress detectable endogenous TMAO in both the plasma and urine, suggesting that the dietary status and specific bacterial taxa affect TMAO concentration. Thus, the gut microbiota plays a specific role in TMAO formation [6].

TMAO is derived from a diet containing choline through the digestion of gut flora which metabolizes choline to trimethylamine (TMA), a gas that is then absorbed into the circulation. TMA can be catalyzed as TMAO by FMO3, a key rate-limiting enzyme in the liver [20]. Specially, FMO3, as a direct FXR target gene, can be activated by bile acids to upregulate expression [20].

In clinical studies, patients who had major adverse cardiovascular events also had higher baseline levels of TMAO than those who did not. The TMAO levels were associated with a 3.4-fold increased mortality risk. TMAO was directly correlated with the severity of HF, independent of the brain natriuretic peptide level and glomerular filtration rate [21]. One to 3 days after acute MI, the circulating TMAO concentrations have been observed to rise. Specifically, the level of TMAO levels in acute MI was associated with prognosis, which predicted adverse outcome of all-cause mortality or reinfarction (death/MI) at 2 years [22].

In functional studies, although the TMAO levels did not directly affect the BP in rats, they prolonged the hypertensive effect of angiotensin II (Ang II) by affecting the structure of receptors and Ang II $[23,24]$. Furthermore, TMAO could also exacerbate cardiac fibrosis and left ventricular (LV) adverse remodeling and dysfunction in a model of cardiac hypertrophy and heart failure [25]. It was found that 3,3dimethyl-1-butanol (DMB), an inhibitor of TMA formation, can prevent cardiac inflammation and fibrosis in western diet- (WD-) induced cardiac dysfunction [26]. In addition, TMAO is associated with cardiovascular burden, such as glycemic control [27], BMI, and renal fibrosis [28].

Regarding mechanisms, the gut microbiota-driven TMA/ FMO3/TMAO pathway is a key regulator of lipid metabolism and inflammation. For example, a recent study suggested that dietary supplementation with TMAO, carnitine, or choline reduced the reverse cholesterol transport (RCT) in mice. RCT can be mediated by either the classic biliary route or the nonbiliary transintestinal cholesterol excretion (TICE) 
TABLE 1: Summary of human trials studying the association between gut microbiome and cardiovascular disease.

\begin{tabular}{|c|c|c|c|c|}
\hline Study & Aim & Method & Outcome & Number \\
\hline $\begin{array}{l}\text { Koren et al. } \\
{[8]}\end{array}$ & $\begin{array}{l}\text { To investigate the effect of oral or gut } \\
\text { microbiota on the microbial composition of } \\
\text { atherosclerotic plaques }\end{array}$ & $\begin{array}{l}\text { qPCR, 16S } \\
\text { rRNA }\end{array}$ & $\begin{array}{c}\text { The abundances of Veillonella and } \\
\text { Streptococcus in atherosclerotic plaques } \\
\text { correlated with their abundance in the } \\
\text { oral cavity }\end{array}$ & $\begin{array}{l}30 \text { adults: } 15 \text { CVD and } \\
15 \text { healthy }\end{array}$ \\
\hline $\begin{array}{l}\text { Hyvärinen } \\
\text { et al. [9] }\end{array}$ & $\begin{array}{c}\text { To investigate the association between } \\
\text { coronary artery disease and periodontal } \\
\text { pathogens }\end{array}$ & $\mathrm{qPCR}$ & $\begin{array}{l}\text { Levels of } A \text {. actinomycetemcomitans } \\
\text { associated with increased risk for CAD }\end{array}$ & $\begin{array}{c}179 \text { CAD, } 166 \text { ACS, } 119 \\
\text { healthy }\end{array}$ \\
\hline $\begin{array}{l}\text { Fak et al. } \\
{[10]}\end{array}$ & $\begin{array}{l}\text { To elucidate the relationship between the } \\
\text { oral microbiota composition and patients } \\
\text { with asymptomatic and symptomatic } \\
\text { atherosclerosis }\end{array}$ & 16S rRNA & $\begin{array}{c}\text { Higher relative abundance of the bacterial } \\
\text { genus Anaeroglobus in symptomatic } \\
\text { atherosclerosis }\end{array}$ & $\begin{array}{c}27 \text { symptomatic AS, } 35 \\
\text { asymptomatic AS, } 30 \\
\text { healthy controls }\end{array}$ \\
\hline $\begin{array}{l}\text { Karlsson } \\
\text { et al. [11] }\end{array}$ & $\begin{array}{c}\text { To investigate whether the gut metagenome } \\
\text { is associated with symptomatic } \\
\text { atherosclerosis }\end{array}$ & MEDUSA & $\begin{array}{c}\text { Genus Collinsella enriched in patients, } \\
\text { Eubacterium and Roseburia enriched in } \\
\text { controls }\end{array}$ & $\begin{array}{l}12 \text { symptomatic AS, } 13 \\
\text { healthy controls }\end{array}$ \\
\hline $\begin{array}{l}\text { Jie et al. } \\
{[12]}\end{array}$ & $\begin{array}{l}\text { To systematically examine the composition } \\
\text { and functional capacity of the gut } \\
\text { microbiome in relation to cardiovascular } \\
\text { diseases }\end{array}$ & $\begin{array}{l}\text { Shotgun } \\
\text { sequencing }\end{array}$ & $\begin{array}{l}\text { Increased abundance of } \\
\text { Enterobacteriaceae and Streptococcus } \\
\text { spp. in patients }\end{array}$ & $\begin{array}{l}218 \text { CVD, } 187 \text { healthy } \\
\text { controls }\end{array}$ \\
\hline $\begin{array}{l}\text { Luedde } \\
\text { et al. [14] }\end{array}$ & $\begin{array}{c}\text { To systematically investigate specific } \\
\text { changes of the intestinal microbiome in HF } \\
\text { patients }\end{array}$ & $16 \mathrm{~S}$ rRNA & $\begin{array}{l}\text { Decreased diversity of the intestinal } \\
\text { microbiome and downregulated key } \\
\text { intestinal bacterial groups, such as } \\
\text { Blautia, Collinsella, Erysipelotrichaceae, } \\
\text { and uncl in HF patients }\end{array}$ & $20 \mathrm{HF}, 20$ controls \\
\hline $\begin{array}{l}\text { Kamo et al. } \\
{[15]}\end{array}$ & $\begin{array}{c}\text { To investigate whether gut microbiota in } \\
\text { HF is associated with aging }\end{array}$ & $16 \mathrm{~S}$ rRNA & $\begin{array}{l}\text { Diminished proportions of Bacteroidetes, } \\
\text { larger quantities of Proteobacteria, and } \\
\text { enriched Lactobacillus in older patients } \\
\text { with HF }\end{array}$ & $\begin{array}{l}12 \mathrm{HF} \text { patients younger } \\
\text { than } 60 \text { years, } 10 \mathrm{HF} \\
\text { patients } 60 \text { years of age } \\
\text { or older }\end{array}$ \\
\hline
\end{tabular}

CAD: coronary artery disease.

pathway [29]. During lipid metabolism, (1) TMAO significantly increases the expression of ABCA1 and ABCG1 in the liver which helps cholesterol efflux to apoA1 as the cholesterol acceptor; (2) TMAO in the gut also markedly reduces the mRNA expression of NPC1L1, which transports cholesterol into the enterocyte from the gut lumen; (3) TMAO reduces the bile acid pool in the liver, which is associated with the classic RCT by reducing synthetic enzymes CYP7A1 and CYP27A1; and (4) TMAO also reduces the expression of ABCG5/8 in the TICE pathway. Therefore, these complex processes inhibit RCT [6]. During proinflammation, (1) TMAO can promote the expression of scavenger receptors (SRs) in the macrophage, such as CD36 and SR-A $[5,30]$; (2) TMAO can also activate the well-known mitogenactivated protein kinase, extracellular signal-related kinase, and nuclear factor- $\kappa \mathrm{B}$ signaling cascade in primary human aortic endothelial cells and vascular smooth muscle cells [31]; (3) TMAO can also promote activation of PKC/NFKB/VCAM-1, which accelerates endothelial dysfunction including decreased endothelial self-repair and increased monocyte adhesion [32]; (4) TMAO may be associated with macrophage polarization in WD-fed rats by increasing TNF- $\alpha$ and interleukin $1 \beta$ (IL-1 $\beta$ ) levels and decreasing anti-inflammatory factor IL-10 levels [23]; and (5) TMAO can significantly trigger oxidative stress and activate TXNIP-NLRP3 inflammasomes to release IL- $1 \beta$ and IL-18 in a dose- and time-dependent manner [33] in vitro. These studies in vivo and vitro pave the way for the clinical regulation of intestinal microorganisms and dietary interventions to prevent the formation of TMAO and improve CVD.

\section{Gut Microbiota and Immunity in CVD}

AS and resulting CVD involve inflammatory reactions in which both the innate and acquired immunities are involved, and anti-inflammatory therapy has received concerns [34]. The gut mucosa as one of the largest immunological active organs in the human body harbors several hundred trillions of bacteria, which are closely tied with the immune system, each influencing and being influenced by the other [35]. Therefore, whether gut microbes interact with CVD in terms of immunity remains unclear.

Recent research revealed that patients with chronic inflammatory bowel diseases, such as Crohn's disease and ulcerative colitis, were at an increased risk of acute arterial events [36], especially young patients [37], and the disease inflammatory state may be an independent risk factor for acute arterial events. Clinical studies and animal experiments have demonstrated that elevated plasma cholesterol attributed to WDs promoted CVD development. In the process, dietary cholesterol initiates intestinal inflammation in epithelial cells [38], disrupts the immune homeostasis, induces gut dysbiosis, and increases CD4+ and CD8+ cell infiltration in distal organs, such as the heart [26]. Chronic inflammation 
of the gut in cases of dysbiosis affects not only itself but also the systemic circulation and central or peripheral tissues. Therefore, we can conclude that the intervention of intestinal immunity may be another novel therapeutic target for the prevention of CVD [34].

4.1. Gut Microbiota and Immunity in AS. The relationship between inflammation and immune responses has been clarified by our understanding of innate and adaptive immunology. First, inflammation as a result of innate and adaptive immunology is produced from the start to the end in AS. Innate immunology responses are initiated by the body's recognition of the signature molecules DAMPs and PAMPs, which could be recognized by pattern recognition receptors (PRRs) [39]. Macrophage PRRs, such as SRs, CD36, and SR-A, internalize oxidation-specific epitopes (i.e., exposed phosphocholine, malondialdehyde, and oxidized cardiolipin). Gut microbe-derived TMAO could enforce the expression of the receptor of SR-A and CD36, which promotes the formation of foam cells whose accumulation within the subendothelium or neointima constitutes the first step in AS. However, the study that germ-free mice were as susceptible to AS as mice with symbiotic bacteria suggested that endogenous substances initiated the inflammation [40]. Endogenous substances, such as cholesterol crystals deposited in mature atherosclerotic lesions, induced inflammation by stimulating the caspase-1-activating NLRP3 inflammasome [41]. In vitro, TMAO can also activate the NLRP3 inflammasome. Meanwhile, the formation of foam cells and the activation of NLRP3 are both early events. Therefore, the intervention of the gut may be considered therapies for the early prevention of coronary AS.

Adaptive immune responses contribute to the development and complications of atherosclerotic lesions. For example, reduced or functionally impaired regulatory $\mathrm{T}$ cells (Treg) lead to an increased incidence of AS [42], and adoptive transfer of Treg into hypercholesterolemic mice reduces lesion development [43]. A study in $\mathrm{Ldll}^{-/-}$AS mice showed that a cholesterol-rich diet can impair the Treg, whereas reversal of a hypercholesterol diet could prevent loss of lesional Treg [44]. Interestingly, an oral anti-CD3 antibody induced Treg and inhibited the development of AS in mice [45]. These observations suggest that the gut intervention can regulate the function and quantity of the Treg for preventing atherosclerotic CVD. In addition, it has been established in germ-free mice or mice treated with antibiotics that intestinal microbes are associated with the differentiation of T cells $[46,47]$.

The role of natural killer T (NKT) cells represents a link between the innate and adaptive immune systems in response to AS, and numerous murine studies have shown that NKT cells are proatherogenic via the activation of their secreted cytokines, such as Th1, Th2, and Th17 cytokines [48]. Adult germ-free mice have increased absolute or relative levels of colonic NKT cells and are immature and hyporesponsive to $\alpha \mathrm{GalCer}$ stimulation of splenic NKT cells. Neonatal germ-free mice can restore their NKT cell number and phenotype when exposed to intestinal microorganisms containing NKT cell antigens. This suggests that the gut microbiota can affect the function of the NKT cells in the organs. Although the direct association of the gut microbiota with AS remains obscure, these research studies provide a perspective that the intervention for the gut may affect the immune cells in CVD.

4.2. Gut Microbiota and Immunity in HF. HF is primarily a clinical diagnosis that develops secondary to either LV systolic or diastolic dysfunction, which is the final outcome of various CVDs [49]. HF with a preserved ejection fraction (EF) and HF with a reduced EF account for $50 \%$ of cases [50]. The levels of numerous proinflammatory cytokines, such as TNF- $\alpha$, IL-1, IL-6, and IL-12, have been observed to be elevated in patients and in animal models with $\mathrm{HF}$ $[51,52]$. Elevated circulating CD14+ monocyte counts 3 days after MI predict a failure to recover the LV systolic function at 3 months post-MI in patients [53]. Endotoxins, an important stimulus for cytokine production in patients with $\mathrm{HF}$ [54], can originate from disrupted intestines resulting from a reduced cardiac output, potentially leading to further exacerbations. An early study on intestinal microbes and HF displayed the perspective of intestinal permeability, that is, gut hypothesis. Whether manipulation of the gut microbiota can attenuate HF and improve long-term outcomes remains to be determined.

\section{Gut Microbiota as a Potential Therapeutic Target in CVD}

The experimental evidence and clinical observations prove the functional link between the intestinal microbiota and CVD, suggesting the theoretical basis to manipulating intestinal microbiota to prevent CVD. The gut microbiota consisting of trillions of commensal microorganisms can express enzymes capable of interacting and interfering with the nutrition and drug we consume, ultimately impacting each other.

First, the use of prebiotics, probiotics, and synbiotics, which is the easiest way to interfere with microbiota composition, had a similar efficacy in reducing LV dysfunctions in obese insulin-resistant rats [55]. For example, probiotics, as a kind of live beneficial bacteria, are administered to reestablish an appropriate intestinal balance (Table 2). In patients with CVDs, consumption of Lactobacillus plantarum (DSM 9843) increased the intestinal microbial diversity compared to a placebo [56]. Probiotic Bifidobacterium animalis subsp. lactis LKM512 could decrease the fecal TMA concentration and BMI in individuals [57]. Lab4 probiotic consortium plus L. plantarum CUL66 possessed anticholesterolemic capabilities in wild-type C57BL/6J mice fed with a high-fat diet. Probiotic Enterobacter aerogenes ZDY01 attenuated cholineinduced TMAO levels via remodeling of the gut microbiota in mice [58]. Unfortunately, the treatment using probiotic L. casei Shirota in patients with metabolic syndrome [59] and VSL\#3 in nonobese men during the consumption of a hypercaloric and high-fat diet cannot attenuate the production of TMAO [60]. Moreover, probiotics consisting of different strains may have various effects on CVD; thus, identifying the appropriate strains is essential for therapy. 
TABLE 2: Summary of the human randomized controlled trials analyzing the effect of probiotic supplementation on CVD.

\begin{tabular}{|c|c|c|c|c|}
\hline Authors & Aim & Population & Main findings & Duration \\
\hline Karlsson et al. [56] & $\begin{array}{l}\text { To clarify the effect of } L \text {. plantarum } \\
\text { (DSM 9843) on intestinal microbiota in } \\
\text { patients with cardiovascular disease }\end{array}$ & $\begin{array}{l}16 \text { males with } \\
\text { atherosclerotic plaque }\end{array}$ & $\begin{array}{l}\text { Increased bacterial diversity and } \\
\text { decreased concentration of } \\
\text { isovaleric } \\
\text { acid and valeric acid }\end{array}$ & 4 weeks \\
\hline Matsumoto et al. [57] & $\begin{array}{l}\text { To investigate the effect of probiotic } \\
\text { Bifidobacterium animalis subsp. lactis } \\
\text { LKM512 on colonic TMA and } \\
\text { atherosclerosis-related makers in } \\
\text { healthy subjects }\end{array}$ & 27 healthy adults & $\begin{array}{c}\text { Reduced fecal TMA } \\
\text { concentration and BMI }\end{array}$ & 12 weeks \\
\hline Tripolt et al. [59] & $\begin{array}{l}\text { To investigate the impact of } \\
\text { Lactobacillus casei Shirota (LcS) on the } \\
\text { formation of TMAO in subjects with } \\
\text { metabolic syndrome }\end{array}$ & $\begin{array}{l}30 \text { subjects with metabolic } \\
\text { syndrome }\end{array}$ & Not affecting levels of TMAO & 12 weeks \\
\hline Boutagy et al. [60] & $\begin{array}{l}\text { To investigate whether multistrain } \\
\text { probiotic VSL\#3 would attenuate the } \\
\text { increase in fasting plasma concentrations } \\
\text { of TMAO following a high-fat diet }\end{array}$ & Nonobese males & Not affecting levels of TMAO & 2 weeks \\
\hline
\end{tabular}

TABLE 3: Nutrition intervention alters gut microbiota composition and improves CVD.

\begin{tabular}{|c|c|c|}
\hline Nutrition intervention & Main findings & Alterations in gut microbiota composition \\
\hline PSE (plant sterol ester) & Cholesterol and aortic plaque $\downarrow$ & Erysipelotrichaceae $\uparrow$ \\
\hline OBG (oat $\beta$-glucan) & Cholesterol, aortic plaque, weight, and fat $\downarrow$ & Butyrate levels and Verrucomicrobia $\uparrow$ \\
\hline High-fiber diet & Improve hypertension and heart failure & Acetate-producing bacteria $\uparrow$ \\
\hline ITF (inulin-type fructans) & Reverse endothelial dysfunction & $\begin{array}{l}\text { Akkermansia } \uparrow \\
\text { Bacterial taxa } \downarrow\end{array}$ \\
\hline Vegetable/fruit juices & $\begin{array}{l}\text { Promote weight loss, increase vasodilator } \\
\text { NO, and decrease lipid oxidation }\end{array}$ & $\begin{array}{c}\text { Firmicutes/Proteobacteria } \downarrow \\
\text { Bacteroidetes } \uparrow \text { Cyanobacteria } \uparrow\end{array}$ \\
\hline$\omega-3$ PUFAs and proanthocyanidins & Plasma cholesterol $\downarrow$ & $\begin{array}{l}\text { Maintains the standard proportions of bacterial } \\
\text { subgroups and their function }\end{array}$ \\
\hline Allicin & TMAO $\downarrow$ & Clostridium $\uparrow$ \\
\hline $\mathrm{DMB}$ & TMAO $\downarrow$ & Inhibit distinct microbial TMA lyases \\
\hline Resveratrol & TMAO $\downarrow$ & Lactobacillus and Bifidobacterium $\uparrow$ \\
\hline Ganoderma lucidum mycelium & Weight, inflammation, and insulin resistance $\downarrow$ & $\begin{array}{c}\text { Firmicutes-to-Bacteroidetes ratios and } \\
\text { endotoxin-bearing Proteobacteria levels } \downarrow\end{array}$ \\
\hline
\end{tabular}

Functional genomics on the most closely related reference strains provided specific treatment strategies to restrain TMA producers and limit their proliferation [61].

Second, the effects of other components in diets can regulate the composition of the intestinal flora (Table 3). In $\mathrm{APOE}^{-/-}$mice fed with a high-fat/cholesterol diet[62], plant sterol ester (PSE), which elevated the relative abundance of Helicobacter, Erysipelotrichaceae, and the genus Roseburia in the gut, is associated with reduced cholesterol levels, aortic plaques, and body fat. Oat $\beta$-glucan (OBG) can elevate butyrate levels and promote Verrucomicrobia population expansion. Thus, it appears to protect against high-fat/cholesterolinduced atherogenesis [63]. High-fiber diets can increase the prevalence of acetate-producing bacteria and improve the levels of Bacteroides acidifaciens, thereby preventing the development of hypertension and $\mathrm{HF}$ in hypertensive mice [64]. Inulin-type fructans (ITFs) can reverse endothelial dysfunction via increased NO-producing bacteria in $\mathrm{APOE}^{-/-}$mice [65]. Vegetable/fruit juices promote weight loss, increase vasodilator NO levels, and decrease lipid oxidation in healthy individuals by decreasing the proportion of the phylum Firmicutes and Proteobacteria and increasing Bacteroidetes and Cyanobacteria in the stool [66]. The combination of $\omega$-3 PUFAs and proanthocyanidins can provide cardiovascular benefits by maintaining the standard proportions of bacterial subgroups in the gut of a healthy rat [67]. Dietary allicin, a potent antimicrobial compound found in garlic, also reduces the transformation of TMAO from Lcarnitine through impacting the gut microbiota in mice [68]. In addition, 3,3-DMB, a structural analog of choline prevalent in wine, olive oil, and grapeseed oil, inhibits TMA production from the gut microbes by inhibiting distinct microbial TMA [69]. Resveratrol, a natural phytoalexin with prebiotic benefits, has been found to attenuate TMAO- 
induced AS by decreasing plasma TMAO levels and increasing hepatic bile acid neosynthesis by changing the intestinal flora [70]. In addition, Ganoderma lucidum (G. lucidum), a medicinal mushroom used in traditional Chinese medicine, has been reported to have antiobesity properties, which are mediated by modulating the composition of the gut microbiota [71]. G. lucidum and its high-molecular-weight polysaccharides may be used as prebiotic agents to prevent gut dysbiosis and obesity-related metabolic disorders in mice fed with a high-fat diet [72].

Given the abovementioned intervention, the gut can regulate microbial community, which can further improve CVDs. When exposed to poison, such as acrolein [73], the gut increased the levels of intestinal Coprococcus and enhanced macrophage atherogenicity in atherosclerotic mice. Thus, gut microbiota remodeling plays a role in the development of CVDs and risks.

\section{Concluding Remarks and Future Perspectives}

The evidence from animal and human studies supports that gut microbiota is in correlation with cardiovascular disease. Unappreciated complexity and considerable diversity of the bacterial microbiome have been gradually uncovered via culture-independent methods. However, the direct relationship between gut microbiota and cardiovascular disease remains obscure. In addition, the diversity of microbiome enhanced the difficulty in identifying strains in correlation with disease state, which restricted therapeutic interventions for the exact target.

Apart from these restrictions, intestinal flora as a barometer of human health is a novel therapeutic target for preventing CVD. Further, tunable expression platforms for the prominent microbiome in which gene expression is controlled by a synthetic inducer may be a good tool. Larger randomized controlled studies of adequate sample size and duration and well-defined therapeutic schedules and endpoints are strongly advisable.

\section{Conflicts of Interest}

The authors of this article have nothing to disclose. No conflicts of interest exist.

\section{References}

[1] D. Mozaffarian, E. J. Benjamin, A. S. Go et al., "Heart disease and stroke statistics-2016 update: a report from the American Heart Association," Circulation, vol. 133, no. 4, pp. e38360, 2016.

[2] R. Jumpertz, D. S. Le, P. J. Turnbaugh et al., "Energy-balance studies reveal associations between gut microbes, caloric load, and nutrient absorption in humans," The American Journal of Clinical Nutrition, vol. 94, no. 1, pp. 58-65, 2011.

[3] F. Purchiaroni, A. Tortora, M. Gabrielli et al., "The role of intestinal microbiota and the immune system," European Review for Medical and Pharmacological Sciences, vol. 17, no. 3, pp. 323-333, 2013.
[4] J. L. Round and S. K. Mazmanian, "The gut microbiota shapes intestinal immune responses during health and disease," Nature Reviews Immunology, vol. 9, no. 5, pp. 313-323, 2009.

[5] Z. Wang, E. Klipfell, B. J. Bennett et al., "Gut flora metabolism of phosphatidylcholine promotes cardiovascular disease," Nature, vol. 472, no. 7341, pp. 57-63, 2011.

[6] R. A. Koeth, Z. Wang, B. S. Levison et al., "Intestinal microbiota metabolism of L-carnitine, a nutrient in red meat, promotes atherosclerosis," Nature Medicine, vol. 19, no. 5, pp. 576-585, 2013.

[7] T. H. Hansen, R. J. Gøbel, T. Hansen, and O. Pedersen, "The gut microbiome in cardio-metabolic health," Genome Medicine, vol. 7, no. 1, p. 33, 2015.

[8] O. Koren, A. Spor, J. Felin et al., "Human oral, gut, and plaque microbiota in patients with atherosclerosis," Proceedings of the National Academy of Sciences of the United States of America, vol. 108, Supplement 1, pp. 4592-4598, 2011.

[9] K. Hyvärinen, P. Mäntylä, K. Buhlin et al., "A common periodontal pathogen has an adverse association with both acute and stable coronary artery disease," Atherosclerosis, vol. 223, no. 2, pp. 478-484, 2012.

[10] F. Fak, V. Tremaroli, G. Bergstrom et al., "Oral microbiota in patients with atherosclerosis," Atherosclerosis, vol. 243, no. 2, pp. 573-578, 2015.

[11] F. H. Karlsson, F. Fak, I. Nookaew et al., "Symptomatic atherosclerosis is associated with an altered gut metagenome," Nature Communications, vol. 3, no. 1, article 1245, 2012.

[12] Z. Jie, H. Xia, S. L. Zhong et al., "The gut microbiome in atherosclerotic cardiovascular disease," Nature Communications, vol. 8, no. 1, article 845, 2017.

[13] W. T. Barrington and A. J. Lusis, "Atherosclerosis: association between the gut microbiome and atherosclerosis," Nature Reviews Cardiology, vol. 14, no. 12, pp. 699-700, 2017.

[14] M. Luedde, T. Winkler, F. A. Heinsen et al., "Heart failure is associated with depletion of core intestinal microbiota," ESC Heart Failure, vol. 4, no. 3, pp. 282-290, 2017.

[15] T. Kamo H. Akazawa et al., "Dysbiosis and compositional alterations with aging in the gut microbiota of patients with heart failure," PLos One, vol. 12, article e0174099, 2017.

[16] J. C. Gregory, J. A. Buffa, E. Org et al., "Transmission of atherosclerosis susceptibility with gut microbial transplantation," Journal of Biological Chemistry, vol. 290, no. 9, pp. 5647-5660, 2015.

[17] Z. X. Wu, S. F. Li, H. Chen et al., "The changes of gut microbiota after acute myocardial infarction in rats," PLoS One, vol. 12, no. 7, article e0180717, 2017.

[18] W. H. Tang, Z. Wang, B. S. Levison et al., "Intestinal microbial metabolism of phosphatidylcholine and cardiovascular risk," The New England Journal of Medicine, vol. 368, no. 17, pp. 1575-1584, 2013.

[19] E. Ierardi, C. Sorrentino, M. Principi, F. Giorgio, G. Losurdo, and A. di Leo, "Intestinal microbial metabolism of phosphatidylcholine: a novel insight in the cardiovascular risk scenario," Hepatobiliary Surgery and Nutrition, vol. 4, no. 4, pp. 289-292, 2015.

[20] B. J. Bennett, T. Q. de Aguiar Vallim, Z. Wang et al., "Trimethylamine-N-oxide, a metabolite associated with atherosclerosis, exhibits complex genetic and dietary regulation," Cell Metabolism, vol. 17, no. 1, pp. 49-60, 2013.

[21] W. H. Tang, Z. Wang, Y. Fan et al., "Prognostic value of elevated levels of intestinal microbe-generated metabolite 
trimethylamine- $N$-oxide in patients with heart failure: refining the gut hypothesis," Journal of the American College of Cardiology, vol. 64, no. 18, pp. 1908-1914, 2014.

[22] T. Suzuki, L. M. Heaney, D. J. Jones, and L. L. Ng, "Trimethylamine $N$-oxide and risk stratification after acute myocardial infarction," Clinical Chemistry, vol. 63, no. 1, pp. 420-428, 2017.

[23] M. Ufnal, R. Jazwiec, M. Dadlez, A. Drapala, M. Sikora, and J. Skrzypecki, "Trimethylamine-N-oxide: a carnitine-derived metabolite that prolongs the hypertensive effect of angiotensin II in rats," Canadian Journal of Cardiology, vol. 30, no. 12, pp. 1700-1705, 2014.

[24] J. Mondal, G. Stirnemann, and B. J. Berne, "When does trimethylamine N-oxide fold a polymer chain and urea unfold it?," The Journal of Physical Chemistry. B, vol. 117, no. 29, pp. 8723-8732, 2013.

[25] C. L. Organ, H. Otsuka, S. Bhushan et al., "Choline diet and its gut microbe-derived metabolite, trimethylamine $\mathrm{N}$-oxide, exacerbate pressure overload-induced heart failure," Circulation: Heart Failure, vol. 9, no. 1, article e002314, 2016.

[26] K. Chen, X. Zheng, M. Feng, D. Li, and H. Zhang, "Gut microbiota-dependent metabolite trimethylamine $\mathrm{N}$-oxide contributes to cardiac dysfunction in western diet-induced obese mice," Frontiers in Physiology, vol. 8, p. 139, 2017.

[27] W. H. Tang, Z. Wang, X. S. Li et al., "Increased trimethylamine $\mathrm{N}$-oxide portends high mortality risk independent of glycemic control in patients with type 2 diabetes mellitus," Clinical Chemistry, vol. 63, no. 1, pp. 297-306, 2017.

[28] J. R. Stubbs, J. A. House, A. J. Ocque et al., "Serum trimethylamine- $N$-oxide is elevated in CKD and correlates with coronary atherosclerosis burden," Journal of the American Society of Nephrology, vol. 27, no. 1, pp. 305-313, 2016.

[29] M. Warrier, D. M. Shih, A. C. Burrows et al., "The TMAOgenerating enzyme flavin monooxygenase 3 is a central regulator of cholesterol balance," Cell Reports, vol. 10, no. 3, pp. 326338, 2015.

[30] M. Febbraio, E. A. Podrez, J. D. Smith et al., "Targeted disruption of the class B scavenger receptor CD36 protects against atherosclerotic lesion development in mice," The Journal of Clinical Investigation, vol. 105, no. 8, pp. 1049-1056, 2000.

[31] M. M. Seldin, Y. Meng, H. Qi et al., "Trimethylamine N-oxide promotes vascular inflammation through signaling of mitogen-activated protein kinase and nuclear factor- $\kappa \mathrm{B}$," Journal of the American Heart Association, vol. 5, no. 2, article e002767, 2016.

[32] G. Ma, B. Pan, Y. Chen et al., "Trimethylamine N-oxide in atherogenesis: impairing endothelial self-repair capacity and enhancing monocyte adhesion," Bioscience Reports, vol. 37, no. 2, 2017.

[33] X. Sun, X. Jiao, Y. Ma et al., “Trimethylamine N-oxide induces inflammation and endothelial dysfunction in human umbilical vein endothelial cells via activating ROS-TXNIP-NLRP3 inflammasome," Biochemical and Biophysical Research Communications, vol. 481, no. 1-2, pp. 63-70, 2016.

[34] T. Yamashita, "Intestinal immunity and gut microbiota in atherogenesis," Journal of Atherosclerosis and Thrombosis, vol. 24, no. 2, pp. 110-119, 2017.

[35] N. Martin-Orozco, Y. Chung, S. H. Chang, Y. H. Wang, and C. Dong, "Th17 cells promote pancreatic inflammation but only induce diabetes efficiently in lymphopenic hosts after conversion into Th1 cells," European Journal of Immunology, vol. 39, no. 1, pp. 216-224, 2009.

[36] J. Kirchgesner, L. Beaugerie, F. Carrat, N. N. Andersen, T. Jess, and M. Schwarzinger, "Increased risk of acute arterial events in young patients and severely active IBD: a nationwide French cohort study," Gut, 2017.

[37] J. Pindjakova, C. Sartini, O. Lo Re et al., "Gut dysbiosis and adaptive immune response in diet-induced obesity vs. systemic inflammation," Frontiers in Microbiology, vol. 8, article 1157, 2017.

[38] F. Progatzky, N. J. Sangha, N. Yoshida et al., "Dietary cholesterol directly induces acute inflammasome-dependent intestinal inflammation," Nature Communications, vol. 5, article 5864, 2014.

[39] J. L. Witztum and A. H. Lichtman, "The influence of innate and adaptive immune responses on atherosclerosis," Annual Review of Pathology: Mechanisms of Disease, vol. 9, no. 1, pp. 73-102, 2014.

[40] S. D. Wright, C. Burton, M. Hernandez et al., "Infectious agents are not necessary for murine atherogenesis," Journal of Experimental Medicine, vol. 191, no. 8, pp. 1437-1442, 2000.

[41] P. Duewell, H. Kono, K. J. Rayner et al., "NLRP3 inflammasomes are required for atherogenesis and activated by cholesterol crystals," Nature, vol. 464, no. 7293, pp. 1357-1361, 2010.

[42] H. Ait-Oufella, B. L. Salomon, S. Potteaux et al., "Natural regulatory $\mathrm{T}$ cells control the development of atherosclerosis in mice," Nature Medicine, vol. 12, no. 2, pp. 178-180, 2006.

[43] A. Mor, D. Planer, G. Luboshits et al., "Role of naturally occurring $\mathrm{CD} 4{ }^{+} \mathrm{CD} 25^{+}$regulatory $\mathrm{T}$ cells in experimental atherosclerosis," Arteriosclerosis, Thrombosis, and Vascular Biology, vol. 27, no. 4, pp. 893-900, 2007.

[44] E. Maganto-Garcia, M. L. Tarrio, N. Grabie, D. X. Bu, and A. H. Lichtman, "Dynamic changes in regulatory $\mathrm{T}$ cells are linked to levels of diet-induced hypercholesterolemia," Circulation, vol. 124, no. 2, pp. 185-195, 2011.

[45] N. Sasaki, T. Yamashita, M. Takeda et al., "Oral anti-CD3 antibody treatment induces regulatory $\mathrm{T}$ cells and inhibits the development of atherosclerosis in mice," Circulation, vol. 120, no. 20, pp. 1996-2005, 2009.

[46] K. Atarashi, J. Nishimura, T. Shima et al., "ATP drives lamina propria $\mathrm{T}_{\mathrm{H}} 17$ cell differentiation," Nature, vol. 455, no. 7214 , pp. 808-812, 2008.

[47] K. Atarashi, T. Tanoue, T. Shima et al., "Induction of colonic regulatory T cells by indigenous Clostridium species," Science, vol. 331, no. 6015, pp. 337-341, 2011.

[48] G. S. Getz and C. A. Reardon, "Natural killer T cells in atherosclerosis," Nature Reviews Cardiology, vol. 14, no. 5, pp. 304314, 2017.

[49] S. A. Dick and S. Epelman, "Chronic heart failure and inflammation: what do we really know?," Circulation Research, vol. 119, no. 1, pp. 159-176, 2016.

[50] G. S. Francis, "Neurohormonal control of heart failure," Cleveland Clinic Journal of Medicine, vol. 78, Supplement 1, pp. S75-S79, 2011.

[51] D. L. Mann, "Innate immunity and the failing heart: the cytokine hypothesis revisited," Circulation Research, vol. 116, no. 7, pp. 1254-1268, 2015.

[52] N. Glezeva, V. Voon, C. Watson et al., "Exaggerated inflammation and monocytosis associate with diastolic dysfunction in heart failure with preserved ejection fraction: evidence of M2 
macrophage activation in disease pathogenesis," Journal of Cardiac Failure, vol. 21, no. 2, pp. 167-177, 2015.

[53] H. Tsujioka, T. Imanishi, H. Ikejima et al., "Impact of heterogeneity of human peripheral blood monocyte subsets on myocardial salvage in patients with primary acute myocardial infarction," Journal of the American College of Cardiology, vol. 54, no. 2, pp. 130-138, 2009.

[54] S. D. Anker, K. R. Egerer, H. D. Volk, W. J. Kox, P. A. PooleWilson, and A. J. S. Coats, "Elevated soluble CD14 receptors and altered cytokines in chronic heart failure," The American Journal of Cardiology, vol. 79, no. 10, pp. 1426-1430, 1997.

[55] W. Tunapong, N. Apaijai, S. Yasom et al., "Chronic treatment with prebiotics, probiotics and synbiotics attenuated cardiac dysfunction by improving cardiac mitochondrial dysfunction in male obese insulin-resistant rats," European Journal of Nutrition, pp. 1-4, 2017.

[56] C. Karlsson, S. Ahrne, G. Molin et al., "Probiotic therapy to men with incipient arteriosclerosis initiates increased bacterial diversity in colon: a randomized controlled trial," Atherosclerosis, vol. 208, no. 1, pp. 228-233, 2010.

[57] M. Matsumoto, Y. Kitada, Y. Shimomura, and Y. Naito, "Bifidobacterium animalis subsp. lactis LKM512 reduces levels of intestinal trimethylamine produced by intestinal microbiota in healthy volunteers: a double-blind, placebocontrolled study," Journal of Functional Foods, vol. 36, pp. 94-101, 2017.

[58] L. Qiu, D. Yang, X. Tao, J. Yu, H. Xiong, and H. Wei, “Enterobacter aerogenes ZDY01 attenuates choline-induced trimethylamine $\mathrm{N}$-oxide levels via remodeling gut microbiota in mice," Journal of Microbiology and Biotechnology, vol. 27, no. 8, pp. 1491-1499, 2017.

[59] N. J. Tripolt, B. Leber, A. Triebl, H. Köfeler, V. Stadlbauer, and H. Sourij, "Effect of Lactobacillus casei Shirota supplementation on trimethylamine- $N$-oxide levels in patients with metabolic syndrome: an open-label, randomized study," Atherosclerosis, vol. 242, no. 1, pp. 141-144, 2015.

[60] N. E. Boutagy, A. P. Neilson, K. L. Osterberg et al., "Probiotic supplementation and trimethylamine- $\mathrm{N}$-oxide production following a high-fat diet," Obesity, vol. 23, no. 12, pp. 2357-2363, 2015.

[61] S. Rath, B. Heidrich, D. H. Pieper, and M. Vital, "Uncovering the trimethylamine-producing bacteria of the human gut microbiota," Microbiome, vol. 5, no. 1, p. 54, 2017.

[62] P. M. Ryan, L. E. London, T. C. Bjorndahl et al., "Microbiome and metabolome modifying effects of several cardiovascular disease interventions in apo- $\mathrm{E}^{-1-}$ mice," Microbiome, vol. 5, no. 1, p. 30, 2017.

[63] A. Everard, C. Belzer, L. Geurts et al., "Cross-talk between Akkermansia muciniphila and intestinal epithelium controls diet-induced obesity," Proceedings of the National Academy of Sciences of the United States of America, vol. 110, no. 22, pp. 9066-9071, 2013.

[64] F. Z. Marques, E. Nelson, P. Y. Chu et al., "High-fiber diet and acetate supplementation change the gut microbiota and prevent the development of hypertension and heart failure in hypertensive mice," Circulation, vol. 135, no. 10, pp. 964977, 2017.

[65] E. Catry, L. B. Bindels, A. Tailleux et al., "Targeting the gut microbiota with inulin-type fructans: preclinical demonstration of a novel approach in the management of endothelial dysfunction," Gut, vol. 67, no. 2, pp. 271-283, 2017.
[66] S. M. Henning, J. Yang, P. Shao et al., "Health benefit of vegetable/fruit juice-based diet: role of microbiome," Scientific Reports, vol. 7, no. 1, p. 2167, 2017.

[67] S. Ramos-Romero, M. Hereu, E. Molinar-Toribio et al., "Effects of the combination of $\omega$-3 PUFAs and proanthocyanidins on the gut microbiota of healthy rats," Food Research International, vol. 97, pp. 364-371, 2017.

[68] W.-K. Wu, S. Panyod, C.-T. Ho, C. H. Kuo, M. S. Wu, and L. Y. Sheen, "Dietary allicin reduces transformation of L-carnitine to TMAO through impact on gut microbiota," Journal of Functional Foods, vol. 15, pp. 408-417, 2015.

[69] Z. Wang, A. B. Roberts, J. A. Buffa et al., "Non-lethal inhibition of gut microbial trimethylamine production for the treatment of atherosclerosis," Cell, vol. 163, no. 7, pp. 1585-1595, 2015.

[70] M. L. Chen, L. Yi, Y. Zhang et al., "Resveratrol attenuates trimethylamine- $\mathrm{N}$-oxide (TMAO)-induced atherosclerosis by regulating TMAO synthesis and bile acid metabolism via remodeling of the gut microbiota," MBio, vol. 7, no. 2, article e02210-15, 2016.

[71] D. Holmes, "Obesity: medicinal mushroom reduces obesity by modulating microbiota," Nature Reviews Endocrinology, vol. 11, no. 9, p. 504, 2015.

[72] C. J. Chang, C. S. Lin, C. C. Lu et al., "Ganoderma lucidum reduces obesity in mice by modulating the composition of the gut microbiota," Nature Communications, vol. 6, no. 1, article 7489, 2015.

[73] O. Rom, H. Korach-Rechtman, T. Hayek et al., “Acrolein increases macrophage atherogenicity in association with gut microbiota remodeling in atherosclerotic mice: protective role for the polyphenol-rich pomegranate juice," Archives of Toxicology, vol. 91, no. 4, pp. 1709-1725, 2017. 


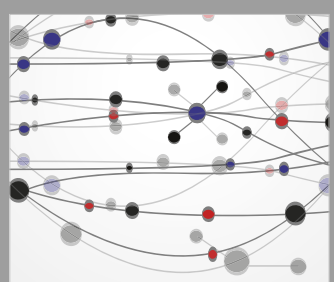

The Scientific World Journal
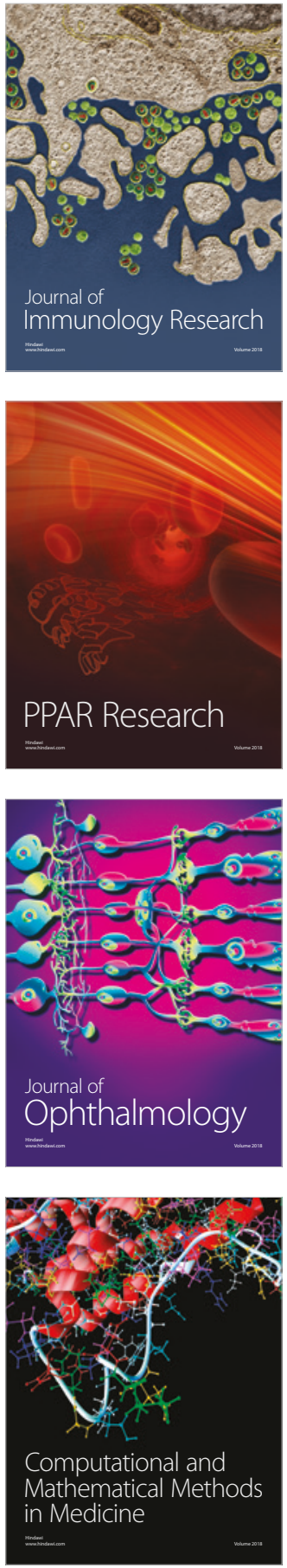

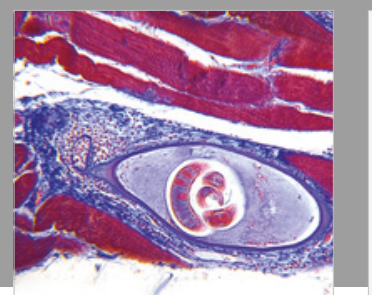

Gastroenterology Research and Practice

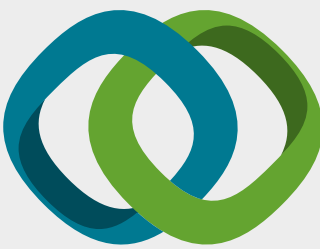

\section{Hindawi}

Submit your manuscripts at

www.hindawi.com
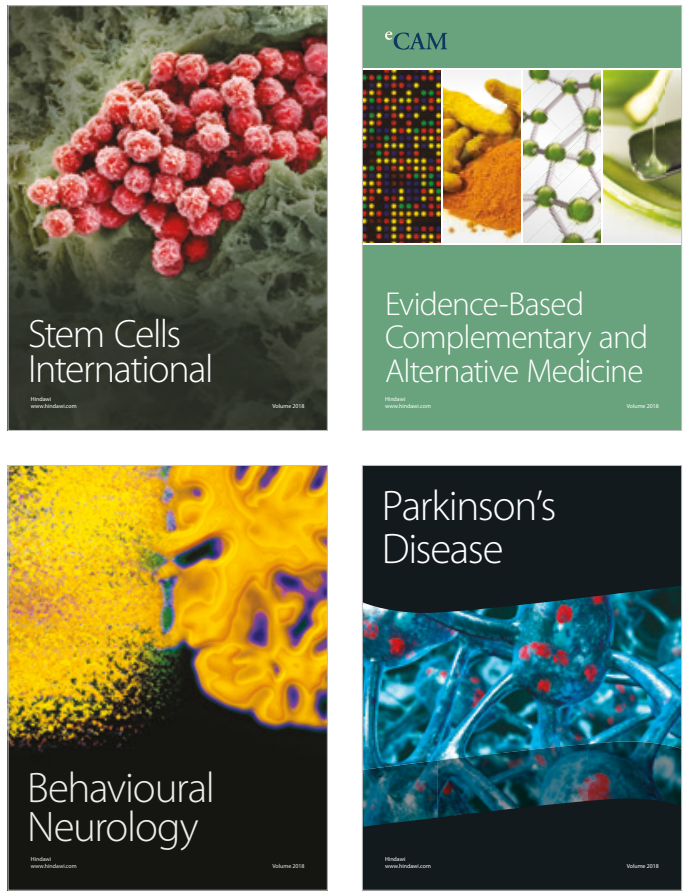

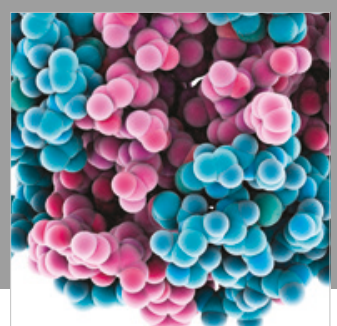

ournal of

Diabetes Research

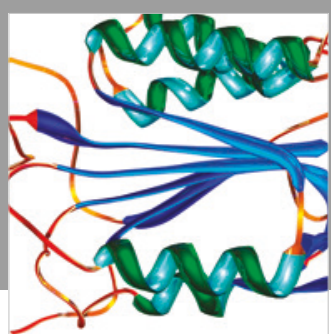

Disease Markers
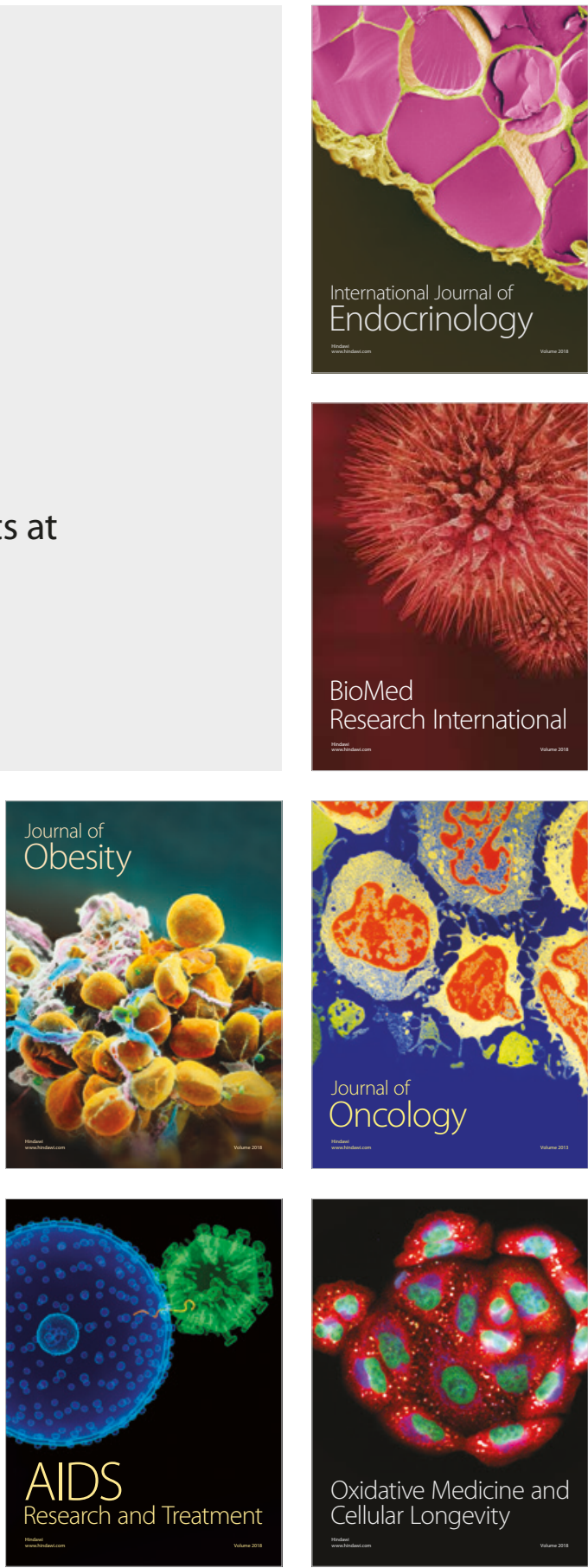